\title{
Building a Conceptual Framework from Polyvagal Theory to Explore Effect of Maternal Speech on Neural Development in Premature Infants
}

\author{
Khlood Bubshait PhD, MSN, RN, BSN (Corresponding author) \\ Dept. of Pediatric Nursing, Imam Abdulrahman bin Faisal University, PO Box 1982, \\ Dammam, Eastern region 32441, Saudi Arabia
}

Tel: +966 0506809075 E-mail: ksboboshet@iau.edu.sa

\author{
Received: January 6, $2021 \quad$ Accepted: April 5, 2021 \\ doi:10.5296/jbls.v12i2.18673 URL: https://doi.org/10.5296/jbls.v12i2.18673
}

\begin{abstract}
The objective of this review was to evaluate the application of Polyvagal theory to: (1) explore relationships between maternal speech and neural development in premature infants; (2) explain influences of moderators, mediators, and confounding variables of early developmental exposure to maternal speech on neural development in premature infants. A positivist ontological approach was undertaken to explore and evaluate the application of Polyvagal theory in the research area of the effect of maternal speech on neural development or heart rate variability in premature infants. The Polyvagal theory was determined to be an effective theory for describing the effect of early developmental exposure to maternal speech on neural development. Major propositions are presented based on the proposed conceptual model, which integrates previous research on exposure to maternal speech, to ultimately enhance neural development in premature infants.
\end{abstract}

Keywords: polyvagal theory, autonomic nervous system, maternal speech, premature infant, neural development

\section{Introduction}

Maternal speech is both a predominant and unique source of early sensory stimulation for the developing fetus (Krueger et al., 2005). Therefore, maternal speech is a logical focus for researchers interested in the development of interventions that use maternal speech as an auditory source of sensory stimulation for premature infants (Krueger et al., 2005; Krueger, Parker, Chiu, \& Theriaque, 2010). While other sources of sound are largely unimodal for the developing fetus (heartbeat, bowel sounds), maternal speech is multimodal (Fifer \& Moon, 1994; Moon et al., 2013). When the mother speaks, not only does the fetus hear her speech, it 
also likely feels her vertebral column and diaphragm gently vibrate and move in synchrony with her speech (Zatorre et al., 2002).

Premature infants experience developmental delays that leave them vulnerable to adverse health outcomes because the natural progression of physiological and sensory development within the womb is interrupted due to their early birth prior to $37^{\text {th }}$ gestational week (Kallioinen et al., 2017; Machado et al. 2017). Exposure to maternal speech, however, has been shown to beneficially influence feeding outcomes and potentiating development of the auditory cortex (Webb et al., 2015).

\subsection{Polyvagal Theory}

Several theoretical models have been used to explain the effect of early developmental exposure to stimuli on the neurobehavioral development of premature infants. These include Probabilistic Epigenesis (Gottlieb, 2007), Self-regulation theory (Als et al., 2004), Perceptual-Learning theory (Gibson, 1969), and the Polyvagal theory (Porges, 1997). After reviewing related literature, the Polyvagal theory was determined to be the most relevant for application to the study of premature infants. The Polyvagal theory is a developmental theory that emphasizes the ontogenetic transitions in neural pathways that regulate conditions of the autonomic nervous system. It describes how the state of the autonomic nervous system provides a neurophysiological platform for optimal co-regulation between the premature infant and environmental stimuli, including their mother (Porges, 2007; Porges and Furman, 2011).

This paper proposes a conceptual framework from a Polyvagal theory to examine the relationship between maternal speech and neural development such as heart rate variability (HRV) and shows empirical evidence for the early developmental exposure to maternal speech. More specifically, this paper aims to: (1) explore relationships between maternal speech and neural development (HRV) in premature infants; (2) explain influences of moderators, mediators, confounding variables of early developmental exposure to maternal speech on neural development in premature infants. This model will advance research about maternal speech associated with neural development and provide a conceptual model to promote the development of therapeutic interventions to enhance neural development in premature infants.

\section{Methods}

The methods used for this paper involved a comprehensive review of the literature for theories relevant to the neurological development of premature infants. We used a four steps process: (1) Identified relevant concepts, (2) Analyzed relationships between concepts, (3) Identified the most relevant theory, and (4) Adapted the selected theory to the study of neurological development in preterm infants.

We first identified relevant concepts through an extensive literature review. The search was performed in the CINAHL, PubMed, Web of Science, and PsycInfo databases using the following key words: "maternal speech effect", "neural developmental outcomes", "behavioral developmental outcomes", "premature infants", "autonomic nervous system", 
and "heart rate variability". The inclusion criteria were peer reviewed articles published before 2018 in English.

Based on this review, we identified the Polyvagal theory as the most comprehensive in terms of the key concepts that describe the components of neural development in infants. Thus, we proceeded to analyze the relational statements between the concepts in order to use the theory to explain the developmental process and predict developmental outcomes in infants. To identify the key theoretical components and adapt them to the study of the impact of mother's voice on premature infant development, we used a substruction process to analyze the Conceptual-Theoretical-Empirical structure (Dulock \& Holzemer, 1991; Walker \& Avant, 2011) of the Polyvagal theory and apply it to our study (Fawcett, 2005).

This process identifies the original theoretical concepts, derives testable empirical concepts related to the impact of maternal speech on neurobehavioral development in premature infants, and identifies possible empirical indicators (measures). In this paper, we focus on the theoretical level, which serves as the foundation for identifying empirical indicators. Finally, The Polyvagal theory was then utilized to propose testable research questions and hypotheses for the role of maternal speech on neurobehavioral development in premature infants.

The Polyvagal theory introduced a new perspective related to autonomic nervous system function (neural development) and behavioral development (Porges, 1997; Porges \& Furman 2011). This theory introduced a new, neurobiological perspective, related to autonomic nervous system (ANS) functioning (neural development) and behavioral development (Porges, 1997; Porges \& Furman 2011). It focused on the neural mechanism as a foundation for the early human developmental process (Porges, 1997). It is an innovative reconceptualization of the interaction between the ANS, which is considered as neural, and behavior (Porges \& Furman 2011).

\section{Results}

The concepts identified from the Polyvagal theory include external environmental stimuli, neural development, and behavioral development as shown in Figure 1 (Porges, 2007; Porges and Furman, 2011). Based on the review of concepts relevant to developmentally appropriate stimulation, the following concepts were then added and applied to the Polyvagal theory in order to create a model or framework maternal speech, heart rate variability, and feeding outcomes. The definitions of concepts are summarized in Table 1. 




Figure 1. Polyvagal theory 2007. Polyvagal theory explains the status of autonomic nervous system in response to external environmental stimuli.

Table 1. Concepts of the Polyvagal theory and the proposed conceptual model

\begin{tabular}{l|l|l}
\hline Main Concepts & \multicolumn{1}{|c}{ Definition } & Possible Empirical Indicator \\
\hline Environmental Stimulus & $\begin{array}{l}\text { A signal (stimulus) that originates } \\
\text { from outside an organism. }\end{array}$ & $\begin{array}{l}\text { Using a CD recording of } \\
\text { mother's speech with specified } \\
\text { decibel, tone, pitch, duration, } \\
\text { frequency, and length for } \\
\text { experimental group versus } \\
\text { control group. }\end{array}$ \\
\hline
\end{tabular}


Neural Development

Behavioral Development

s

The acquisition of both basic
skills and the development of
more complex behaviors (Porges,
1997)

The acquisition of both basic
skills and the development of
more complex behaviors (Porges,
1997)

The acquisition of both basic
skills and the development of
more complex behaviors (Porges,
1997). goal-directed states of consciousness, in reciprocal interaction with the caregiving environment, ever-increasing resiliency capacity to learn from complex stimuli.
The ability of infants to use

Depends on the social engagement or developed skills such as Number of days to full oral feeding.

\section{Proposed Concepts}

\begin{tabular}{|c|c|c|}
\hline $\begin{array}{l}\text { Maternal Speech } \\
\text { (Motherese) }\end{array}$ & $\begin{array}{l}\text { Mother speech to the infant in a } \\
\text { very high-pitched voice along } \\
\text { with a slower rhythm and an } \\
\text { inflated tone. }\end{array}$ & $\begin{array}{l}\text { - Intensity: } 45 \text { decibel } \\
\text { - } \text { Frequency: Twice a day } \\
\text { - Duration: } 45 \text { seconds. } \\
\text { - Measurement: Test } \\
\text { session once a week. }\end{array}$ \\
\hline Heart Rate Variability & $\begin{array}{l}\text { Beat-to-beat variations of the RR } \\
\text { interval length constitutes a } \\
\text { relevant non-invasive tool to } \\
\text { assess the autonomic nervous } \\
\text { system function. }\end{array}$ & $\begin{array}{l}\text { Spectral Analysis of high } \\
\text { frequency power }\end{array}$ \\
\hline
\end{tabular}

\section{Mediator}

Neurophysiological

Regulation
A process in which the decided output to executive action in the brain must result from the processing of innumerable inputs from the environment.

\section{Moderator}

Using magnetic resonance image, Electroencephalography

\begin{tabular}{l|l|l}
\hline Age & The number of weeks of life & Weeks of life \\
\hline
\end{tabular}


Gender

The role of a male or female in society, known as a gender role
Infants gender assignment to either male or female after birth.

Table 1. Continued.

Main Concepts

Definition

Possible Empirical Indicator

\section{Possible Confounding Variables}

\begin{tabular}{l|l|l}
\hline $\begin{array}{l}\text { Maternal Variation in } \\
\text { Recitation }\end{array}$ & $\begin{array}{l}\text { The difference in the frequency, } \\
\text { duration and level of decibel of } \\
\text { mother speech. }\end{array}$ & $\begin{array}{l}\text { Frequency range, duration, and } \\
\text { level of decibels. }\end{array}$ \\
\hline $\begin{array}{l}\text { Additional Sensory } \\
\text { Stimuli }\end{array}$ & $\begin{array}{l}\text { Signals from the environment } \\
\text { that interfere with the accuracy } \\
\text { measures of cause and effect } \\
\text { (visual, hear, touch). }\end{array}$ & $\begin{array}{l}\text { Maternal log (to account the } \\
\text { average time mothers touch, and } \\
\text { speak to their infants). }\end{array}$ \\
\hline Respiratory Support & $\begin{array}{l}\text { Invasive mechanical ventilation: } \\
\text { requires endotracheal intubation } \\
\text { through the mouth into the } \\
\text { trachea and attached to a a } \\
\text { ventilator or tracheostomy }\end{array}$ & $\begin{array}{l}\text { The Intensive Care Unit team } \\
\text { sets the number of breaths and } \\
\text { the amount of volume or } \\
\text { pressure given at each breath. }\end{array}$ \\
\hline Some Medications & $\begin{array}{l}\text { Drug used to treat, or prevent } \\
\text { disease such as anticholinergic } \\
\text { drugs. }\end{array}$ & $\begin{array}{l}\text { Blood works result, spectral } \\
\text { analysis of heart rate variability. }\end{array}$ \\
\hline
\end{tabular}

The relationships between concepts based on the Polyvagal theory were then established. Porges and colleagues posit that features presenting in the external environment influence the neurophysiological regulation in the brain and stimulate the vagus nerve, which is responsible for neural and behavioral development (Beauchaine et al., 2010; Porges, 1997; Porges, 2007; Porges and Furman, 2011; Porges, 2017). Therefore, depending on the information derived from sensory stimuli in the external environment and the neurological process of neuroception, individuals respond or behave indifferently depending upon the situation: safe, dangerous, or life threatening. Whichever of these three neurological subsystems is activated inhibits the other two subsystems (Porges, 2017).

\subsection{Application of Polyvagal Theory to Maternal Speech}

The Polyvagal theory is directly applicable to research questions related to the effect of maternal speech on the neural development in premature infants (Figure 2). 


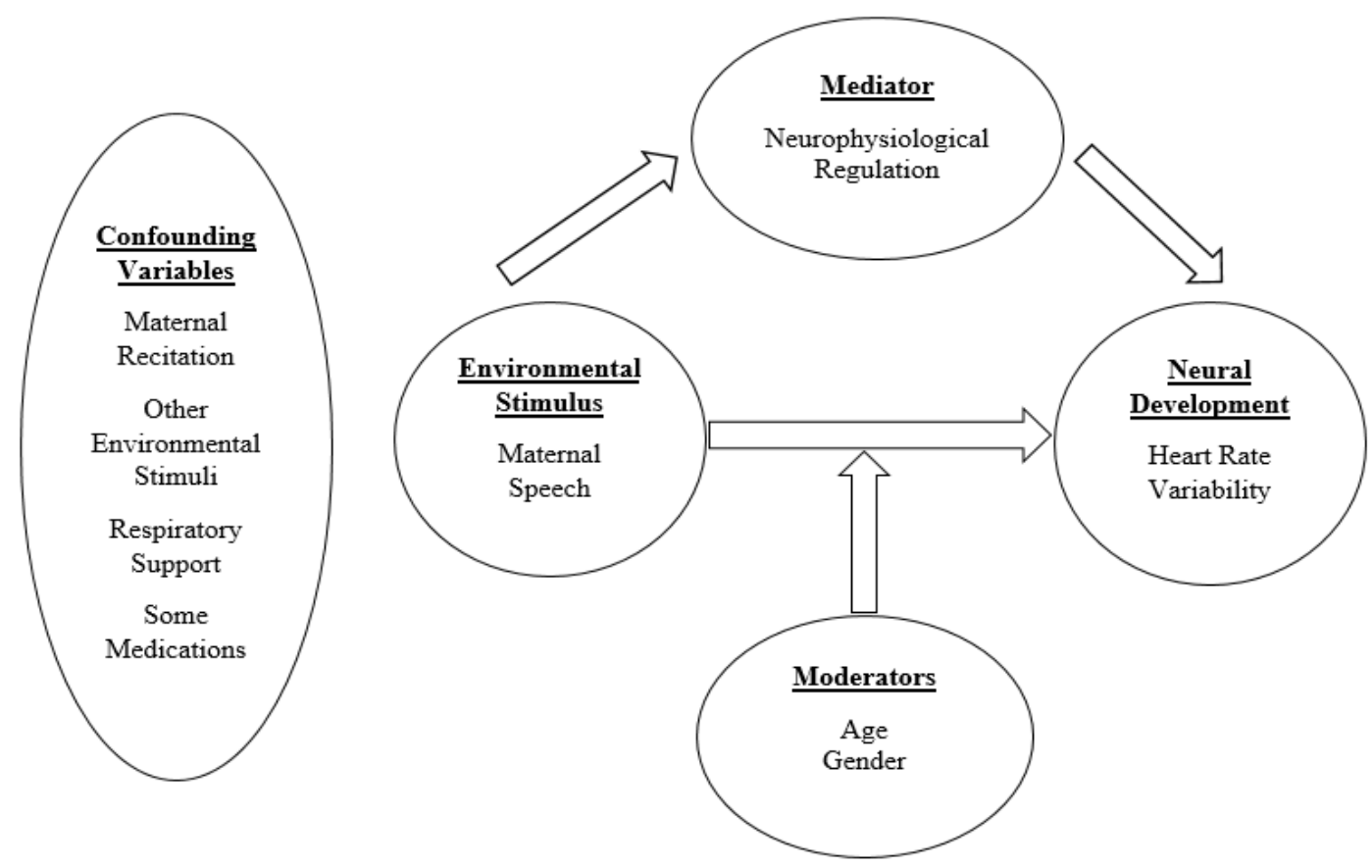

Figure 2. Proposed conceptual model. Conceptual model regarding the effect of early developmental exposure to maternal speech on neural development in premature infants

Major components of the proposed model include maternal speech (external environmental stimulus), neural development such as heart rate variability. Mediators and moderators of the relationship between maternal speech and neurobehavioral development of premature infants have not been extensively studied. Therefore, some variables including mediator (neurophysiological regulation), moderators (age, gender), and confounders (maternal variation in recitation, additional sensory stimulation, respiratory support, medications) were added to the proposed theoretical model. A conceptualization of the theory's pathways and interaction between key variables are illustrated in Table 2 .

Table 2. Conceptual-Theoretical-Empirical structure for the study of the effect of maternal speech on neural development in premature infants

\begin{tabular}{lccc} 
& Environment & $\begin{array}{c}\text { Neural } \\
\text { Development }\end{array}$ \\
\cline { 2 - 4 } & CONSTRUCTS & $\begin{array}{c}\text { Outside the } \\
\text { body }\end{array}$ & $\begin{array}{c}\text { Autonomic } \\
\text { nervous system }\end{array}$
\end{tabular}




\begin{tabular}{|c|c|c|c|}
\hline 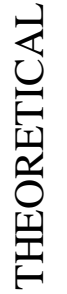 & CONCEPTS & Maternal speech & $\begin{array}{l}\text { Heart rate } \\
\text { variability }\end{array}$ \\
\hline  & MEASURES & $\begin{array}{l}\text { Exposure and } \\
\text { non-exposure } \\
\text { between } \\
\text { experimental } \\
\text { and control } \\
\text { group }\end{array}$ & Electrocardiogram \\
\hline 离 & SCORES & $\begin{array}{l}\text { Intensity } 45-50 \text {. } \\
\text { Once a week. } \\
45 \text { seconds. }\end{array}$ & $\begin{array}{l}\text { Spectral analysis } \\
\text { (high frequency) }\end{array}$ \\
\hline
\end{tabular}

Maternal speech relationships with neurophysiological regulation and neural development can be observed. In other words, maternal speech serves as an external environmental stimulus, which influences the neurophysiological regulation in the brain that impacts neural development (Perez \& Sundheim, 2018). Maternal speech can therefore directly influence neural developmental factors such as heart rate variability via neurophysiological regulation (Perez \& Sundheim, 2018). The wide effects of maternal speech on brain function (neurophysiological regulation), encompassing auditory perception, language processing, attention, memory, and emotion suggests that use of maternal speech is a therapeutic tool in premature infants at neurodevelopmental risk (Särkämö et al., 2013).

Moderators are variables that influence the strength of the relationship between two other variables, for example age and gender (Grossman \& Taylor, 2007). Gender moderates the relationship between maternal speech exposure and neural development (Morse et al., 2006; Thomas et al., 2008). The relationship between maternal speech and neural development is different for males and females. The relationship between maternal speech exposure and neural development is different for infants with younger gestational age (GA) and more advanced GA (Krueger, van Oostrom, \& Shuster, 2010). The more advanced GA infants showed normal range of frequency measures of HRV (including high frequency) than younger infants (Krueger, Parker, Chiu, \& Theriaque, 2010; Krueger, van Oostrom, \& Shuster, 2010). Therefore, age moderates the relationship between maternal speech exposure and neural development. 
Neurophysiological development (reflects the function of cerebral cortex in the brain) mediates the relationship between maternal speech and neural development (Scher et al., 2011). The cerebral cortex and the auditory sensory systems are mostly established during a critical period in the neonatal life when neural circuitry is first generated and are highly dependent on the external environment stimuli (acoustic stimuli) (Nosarti et al. 2014). For example, appropriate exposure to a suitable maternal speech (less ta 45 decibels, daily exposure) may contribute to increased neurophysiological regulation in the brain of premature infants and result in improved neural development. In contrast, persistent stress that results from inappropriate exposure to an unsuitable maternal speech (more than 45 decibels, decreased time of exposure) may contribute to neurophysiological dysfunction in the brain of premature infants and result in decreased neural development._Increased neurophysiological regulation in the brain contributes to improved neural development as a result of exposure to suitable sounds (Lordier et al., 2019; Vandormael at al., 2019). Furthermore, decreased neurophysiological regulation in the brain contributes to decreased neural development (McAnulty et al., 2009).

With respect to Polyvagal theory, confounding variables such as maternal variation in recitation, additional sensory stimulation, respiratory support, and some medications influence and potentially change the effect of the relationship between maternal speech, neurophysiological regulation, and neural development. These variables can also interact with moderators such as age and gender in order to further influence or change the effect between these relationships within the model.

Variation in the style of maternal recitation including the frequency range, duration, and level of decibels is expected during research conducted in premature infants (Krueger, Parker, Chiu, \& Theriaque, 2010; Krueger, van Oostrom, \& Shuster, 2010). According to the American Academy of Pediatrics (1997), safe sound levels of external stimuli for premature infants should be between less than or equal to 45 decibel (dB) (American Academy of Pediatrics, 1997). The appropriate use of maternal speech (sound level of equal or less than $45 \mathrm{~dB}$.) enhances the early maturation of ANS in hospitalized premature infants (Krueger, Parker, Chiu, \& Theriaque, 2010; Krueger, van Oostrom, \& Shuster, 2010).

Additional sensory stimulation is another confounding variable that may affect the influence maternal speech on neural development in premature infants (Krueger, Parker, Chiu, \& Theriaque, 2010; Krueger, van Oostrom, \& Shuster, 2010). It is unknown how much stimuli the premature infants are exposed to in NICU such as excessive auditory, visual, tactile stimulation. These stimuli might interfere with the influence of maternal speech on neural development in premature infants. Krueger and colleagues used maternal log to control for maternal contact in each infant (Krueger, Parker, Chiu, \& Theriaque, 2010).

Respiratory support is a possible confounding variable that may influences the maturation of ANS and measurement of HRV due to the hemodynamic alterations that result during weaning from mechanical ventilation (Alonzo, \& Fairchild, 2017; Pomeranz et al., 1985; Porges, 1997). Additionally, HRV can be significantly influenced by various categories of medications; thus, the impact should be considered while interpreting HRV. Furthermore, 
some medications such as $\beta_{2}$ agonists and anticholinergic drug are known to affect the HRV measures and are more commonly used in critically ill patients (Penttilä et al., 2005).

Several measures have been identified that are consistent with constructs within the model, and that could be tested or applied in different studies by using a Conceptual-Theoretical-Empirical structure. For example, in the study of early developmental exposure to maternal speech on heart rate variability development in premature infants (Krueger, van Oostrom, \& Shuster, 2010), the conceptual structure includes the main construct of the Polyvagal theory. The theoretical structure includes the variable of interest for the study under each construct of Polyvagal theory. The empirical structure section includes the measures and scores of variables of interest for the proposed application as seen in Table 2 .

\subsubsection{Use of the Polyvagal Theory to Propose Hypotheses}

Relational statements connect the concepts presented in the proposed theoretical model. The proposed theoretical framework facilitates the investigation of concepts using relevant empirical indicators and provides a means to develop systematic knowledge of early developmental exposure and infant development.

Several possible hypotheses can be derived from the proposed conceptual framework including:

- Maternal speech will affect neurophysiological regulation in premature infants

- Maternal speech will indirectly affect neurobehavioral development in infants.

- Age and gender will moderate neural development in response to maternal speech.

- Neurophysiological regulation will mediate the relationship of maternal speech on neurobehvaioral development.

\section{Discussion}

The proposed conceptual framework, adapted from the Polyvagal theory, uses a multidimensional model to explain how exposure to maternal speech and other auditory stimuli in premature infants in NICUs might affect neural and behavioral development. Previous studies have demonstrated beneficial impacts of early developmental exposure to maternal speech on neurobehavioral development in premature infants. While empirical studies have shown beneficial effects in early development, the theoretical basis for proposing these beneficial effects is not widely understood. To our knowledge, there are limited current theories specifically addressing the role of maternal speech in the neurobehavioral development of premature infants. The proposed conceptual framework incorporates the status of autonomic nervous system (vagal tone activity) and its response to external environmental stimuli. The model provides a framework for future studies to empirically test the hypothesized associations between early developmental exposure to sound experiences and neural development.

While few studies have reported a theoretical framework to explain the effect of maternal 
speech on neurobehavioral development in premature infants. There are several theoretical frameworks that have been used to describe, explain, and predict the effect of early developmental exposure to external stimuli on development.

In general, the Polyvagal theory encompasses the most relevant concepts to describe and explain the effect of early developmental exposure to maternal speech on the neurobehavioral development of premature infants. Predictions the ultimate goal for all research and central to health science research as preventive and therapeutic interventions are prescribed or recommended on implicit or explicit expectations about future health outcomes.

Studies are needed to explore the most effective environmental stimuli that encourage infants' development. Future directions may include comparing the unimodal characteristics of a maternal recording compared to the multimodal characteristics of 'live' maternal interactions. Additionally, more studies are needed to identify factors that moderate the effect of maternal speech in the infants' development.

\section{Conclusion}

To date, there are limited theoretical models to explain early developmental exposure to maternal speech associated with neural development (Filippa et al., 2017; Krueger, Oostrom, $\&$ Shuster, 2010). The proposed conceptual model provides a basis for understanding how early developmental exposure to maternal speech influences the neural development in premature infants. Findings from this proposed conceptual model may be used to guide development and testing of interventions to describe, explain, and predict for salient, external factors that potentially influence neural development in premature infants.

\section{Data Availability}

Data sharing not applicable to this article as no datasets were generated or analyzed in the current theoretical review.

\section{Funding}

This review received no specific grant from any funding agency in the public, commercial, or not-for-profit sectors.

\section{Acknowledgments}

This work was supported in part by University of Florida, college of Nursing, Gainesville, Florida and Imam Abdulrahman bin Faisal University, College of Nursing, Dammam, KSA.

\section{Conflict of interest}

The author declares no conflict of interest.

\section{References}

Agrawal, S., Rao, S. C., Bulsara, M. K., \& Patole, S. K. (2018). Prevalence of autism spectrum disorder in preterm infants: a meta-analysis. Pediatrics, 142(3), e20180134. https://doi.org/10.1542/peds.2018-0134 
Alonzo, C. J., \& Fairchild, K. D. (2017). Dexamethasone effect on heart rate variability in preterm infants on mechanical ventilation. Journal of neonatal-perinatal medicine, 10(4), 425-430. https://doi.org/10.3233/NPM-16157

Als, H., Duffy, F., McAnulty, G., Rivkin, M., Vajapeyam, S., Mulkern,..,Eichenwald, E. C. (2004). Early experience alters brain function and structure. Journal of Pediatrics , 113(4), 846-857. https://doi.org/10.1542/peds.113.4.846

American Academy of Pediatrics (1997). Committee on Environmental Health. Noise: A hazard for the fetus and newborn. Pediatrics, 100,724-727.

Aucott, S., Donohue, P. K., Atkins, E., \& Allen, M. C. (2002). Neurodevelopmental care in the NICU. Mental retardation and developmental disabilities research reviews, 8(4), 298-308. https://doi.org/10.1002/mrdd.10040

Barfield, W. D. (2018). Public health implications of very preterm birth. Clinics in perinatology, 45(3), 565-577. https://doi.org/10.1016/j.clp.2018.05.007

Beauchaine, T. P., Hinshaw, S. P., \& Pang, K. L. (2010). Comorbidity of attention-deficit/hyperactivity disorder and early-onset conduct disorder: Biological, environmental, and developmental mechanisms. Journal of Clinical Psychology: Science and Practice, 17(4), 327-336. https://doi/full/10.1111/j.1468-2850.2010.01224.x

Chapman, J. S. (1978). The relationship between auditory stimulation and gross motoractivity of short-gestation infants. Journal of Research in nursing \& health, 1(1), 29-36. https://doi.org/10.1002/nur.4770010107

Cherland, E. (2012). The Polyvagal theory: Neurophysiological foundations of emotions, attachment, communication, self-regulation. Journal of the Canadian Academy of Child and Adolescent Psychiatry, 21(4), 313. PMCID: PMC3490536

Chorna, O. D., Slaughter, J. C., Wang, L., Stark, A. R., \& Maitre, N. L. (2014). A pacifier-activated music player with mother's voice improves oral feeding in preterm infants. Pediatrics, 133(3), 462-468. http://doi.org/10.1542/peds.2013-2547

Dulock, H. L., \& Holzemer, W. L. (1991). Substruction: Improving the linkage from theory to method. Nursing Science Quarterly, 4(2), 83-87.

https://doi.org/10.1177/089431849100400209

Fawcett, J. (2005). Implementing nursing models and theories in practice. Chapter 2 in Contemporary Nursing Knowledge: Analysis and Evaluation of Nursing Models and Theories ( $2^{\text {nd }}$ edition). F.A. Davis, Philadelphia. (p. 31-48).

Fawcett, J., DeSanto-Madeya, S. (2012). Contemporary Nursing Knowledge: Analysis and Evaluation of Nursing Models and Theories, 3rd ed.; F.A. Davis Company: Philadelphia, PA, USA. https://doi.org/10.1111/j.1469-8749.2003.tb00343.x

Fifer, W. P., \& Moon, C. M. (1994). The role of mother's voice in the organization of brain function in the newborn. Journal of Acta Paediatrica, 83, 86-93. 
https://doi.org/10.1111/j.1651-2227.1994.tb13270.x

Figueiredo, B., Pinto, T. M., Pacheco, A., \& Field, T. (2017). Fetal heart rate variability mediates prenatal depression effects on neonatal neurobehavioral maturity. Biological Psychology, 123, 294-301. https://doi.org/10.1016/j.biopsycho.2016.10.013

Filippa, M., Panza, C., Ferrari, F., Frassoldati, R., Kuhn, P., Balduzzi, S., \& D'Amico, R. (2017). Systematic review of maternal voice interventions demonstrates increased stability in preterm infants. Acta paediatrica, 106(8), 1220-1229. https://doi.org/10.1111/apa.13832

Gibson, E. J. (1969). Principles of perceptual learning and development. New York: Appleton-Century-Crofts.

Gottlieb, G. (2007). Probabilistic epigenesis. Journal of Developmental science, 10(1), 1-11. https://doi.org/10.1111/j.1467-7687.2007.00556.x

Grossman, P., \& Taylor, E. W. (2007). Toward understanding respiratory sinus arrhythmia: relations to cardiac vagal tone, evolution and biobehavioral functions. Journal of Biological psychology, 74(2), 263-285. https://doi.org/10.1016/j.biopsycho.2005.11.014

Kallioinen, M., Eadon, H., Murphy, M. S., \& Baird, G. (2017). Developmental follow-up of children and young people born preterm: summary of NICE guidance. British Medical Journal, 358. https://doi.org/10.1080/01942638.2018.1503212

Korja, R., Latva, R., \& Lehtonen, L. (2012). The effects of preterm birth on mother-infant interaction and attachment during the infant's first two years. Acta obstetricia et gynecologica Scandinavica, 91(2), 164-173. https://doi.org/10.1111/j.1600-0412.2011.01304.x

Krueger, C., Holditch-Davis, D., Quint, S., \& DeCasper, A. (2005). Recurring auditory experience in the 28-to 34-week-old fetus. Journal of Infant Behavior and Development, 27(4), 537-543. https://doi.org/10.1016/j.infbeh.2004.03.001

Krueger, C., Parker, L., Chiu, S.-H., \& Theriaque, D. (2010). Maternal Voice and Short-Term Outcomes in Preterm Infants. Journal of Developmental Psychobiology, 52(2), 205-212. https://doi.org/10.1002/dev.20426

Krueger, C., van Oostrom, J. H., \& Shuster, J. (2010). A Longitudinal Description of Heart Rate Variability in 28-34-Week-Old Preterm Infants. Journal of Biological Research for Nursing, 11(3), 261-268. https://doi.org/10.1177/1099800409341175

Lordier, L., Meskaldji, D. E., Grouiller, F., Pittet, M. P., Vollenweider, A., Vasung, L. ... \& Hüppi, P. S. (2019). Music in premature infants enhances high-level cognitive brain networks. Proceedings of the National Academy of Sciences, 116(24), 12103-12108. https://doi.org/10.1073/pnas.1817536116

Machado, A. C. C. D. P., Oliveira, S. R. D., Magalhães, L. D. C., Miranda, D. M. D., \& Bouzada, M. C. F. (2017). Sensory processing during childhood in preterm infants: a systematic review. Journal of Revista Paulista de Pediatria, 35(1), 92-101. http://dx.doi.org/10.1590/1984-0462/;2017;35;1;00008 
McAnulty, G. B., Butler, S. C., Bernstein, J. H., Als, H., Duffy, F. H., \& Zurakowski, D. (2009). Effects of the Newborn Individualized Developmental Care and Assessment Program (NIDCAP) at age 8 years: preliminary data. Clinical pediatrics, 49(3), 258-270. https://doi.org/10.1177/0009922809335668

Moon, C., Lagercrantz, H., \& Kuhl, P. K. (2013). Language experienced in utero affects vowel perception after birth: A two-country study. Journal of Acta Paediatrica, 102(2), 156-160. https://doi.org/10.1111/apa.12098

Morse, S. B., Wu, S. S., Ma, C., Ariet, M., Resnick, M., \& Roth, J. (2006). Racial and gender differences in the viability of extremely low birth weight infants: a population-based study. Pediatrics, 117(1), e106-e112.

http://doi.org/ 10.1542/peds.2005-1286

Nosarti, C., Nam, K. W., Walshe, M., Murray, R. M., Cuddy, M., Rifkin, L., \& Allin, M. P. (2014). Preterm birth and structural brain alterations in early adulthood. NeuroImage: Clinical, 6, 180-191. http://dx.doi.org/10.1016/j.nicl.2014.08.005

Penttilä, J., Kuusela, T., \& Scheinin, H. (2005). Analysis of rapid heart rate variability in the assessment of anticholinergic drug effects in humans. European journal of clinical pharmacology, 61(8), 559-565. https://doi.org/10.1007/s00228-005-0953-2

Perez, L. M., \& Sundheim, C. J. (2018). Mother-infant psychotherapy informed by Polyvagal theory. Journal of Infant, Child, and Adolescent Psychotherapy, 17(3), 145-153. https://doi.org/10.1080/15289168.2018.1482133.

Pomeranz, B., Macaulay, R. J., Caudill, M. A., Kutz, I., Adam, D., Gordon, D., ... \& Cohen, R. J. (1985). Assessment of autonomic function in humans by heart rate spectral analysis. American Journal of Physiology-Heart and Circulatory Physiology, 248(1), H151-H153. https://doi.org/10.1152/ajpheart.1985.248.1.H151

Porges, S. W. (1997). Emotion: an evolutionary by-product of the neural regulation of the autonomic nervous system. Journal of Annals of the New York Academy of Sciences, 807(1), 62-77. https://doi.org/10.1111/j.1749-6632.1997.tb51913.x

Porges, S. W. (2007). The Polyvagal perspective. Biological psychology, 74(2), 116-143. https://doi.org/10.1016/j.biopsycho.2006.06.009

Porges, S. W. (2017). The pocket guide to the Polyvagal theory: The transformative power of feeling safe. New York: WW Norton \& Co.

Porges, S. W., \& Furman, S. A. (2011). The early development of the autonomic nervous system provides a neural platform for social behavior: A Polyvagal perspective. Infant and child development, 20(1), 106-118. https://doi.org/10.1002/icd.688

Porges, S. W., Davila, M. I., Lewis, G. F., Kolacz, J., Okonmah-Obazee, S., Hane, A. A., ... \& Welch, M. G. (2019). Autonomic regulation of preterm infants is enhanced by Family Nurture Intervention. Developmental psychobiology, 61(6), 942-952.

https://doi.org/10.1002/dev.21841 
Rand, K., \& Lahav, A. (2014). Maternal sounds elicit lower heart rate in preterm newborns in the first month of life. Journal of Early human development, 90(10), 679-683. https://doi.org/10.1016/j.earlhumdev.2014.07.016

Särkämö, T., Tervaniemi, M., \& Huotilainen, M. (2013). Music perception and cognition: development, neural basis, and rehabilitative use of music. Wiley Interdisciplinary Reviews: Cognitive Science, 4(4), 441-451. doi: 10.1002/wcs.1237

Scher, M. S., Johnson, M. W., Ludington, S. M., \& Loparo, K. (2011). Physiologic brain dysmaturity in late preterm infants. Journal of Pediatric research, 70(5), 524. https://doi.org/10.1203/PDR.0b013e31822f24af

Thomas, K., Tsai, S. Y., \& Brown, S. (2008). State change in preterm infants in response to nursing caregiving: Possible gender effects. Journal of Neonatal Network, 27(1), 15-22. https://doi.org/10.1891/0730-0832.27.1.15

Vandormael, C., Schoenhals, L., Hüppi, P. S., Filippa, M., \& Borradori Tolsa, C. (2019).

Language in Preterm Born Children: Atypical Development and Effects of Early Interventions on Neuroplasticity. Neural plasticity, 2019. https://doi.org/10.1155/2019/6873270

Walker, L. O., \& Avant, K. C. (2011). Strategies for theory construction in nursing (5th ed.). Norwalk, CT: Appleton \& Lange.

Webb, A. R., Heller, H. T., Benson, C. B., \& Lahav, A. (2015). Mother's voice and heartbeat sounds elicit auditory plasticity in the human brain before full gestation. Journal of Proceedings of the National Academy of Sciences, 201414924. https://doi.org/10.1073/pnas.1414924112

Weber, A., \& Harrison, T. M. (2019). Reducing toxic stress in the neonatal intensive care unit to improve infant outcomes. Nursing Outlook, 67(2), 169-189. https://doi.org/10.1016/j.outlook.2018.11.002

Zatorre, R. J., Belin, P., \& Penhune, V. B. (2002). Structure and function of auditory cortex: music and speech. Trends in Cognitive Sciences, 6(1), 37-46. http://doi.org/10.1016/S1464-6613 (00)01816-7

Zimmerman, E., Keunen, K., Norton, M., \& Lahav, A. (2013). Weight gain velocity in very low-birth-weight infants: effects of exposure to biological maternal sounds. American Journal of Perinatology, 30(10), 863-870. https://doi.org/10.1055/s-0033-1333669

\section{Copyright Disclaimer}

Copyright for this article is retained by the author(s), with first publication rights granted to the journal.

This is an open-access article distributed under the terms and conditions of the Creative Commons Attribution license (http://creativecommons.org/licenses/by/4.0/). 